\title{
Annual Report on External Quality Assessment Scheme in Clinical Microbiology in Korea (2013)
}

Young Jin $\mathrm{Ko}^{1}$, Mi-Na Kim ${ }^{1}$, Eui Chong $\mathrm{Kim}^{2}$, Jong Hee Shin ${ }^{3}$, Nam Yong Lee ${ }^{4}$, Sunjoo Kim ${ }^{5}$, Seok Hoon Jeong 6 , Jae-Seok Kim ${ }^{7}$, Chang Ki Kim ${ }^{8}$, Hye Gyung $\mathrm{Bae}^{9}$, Nam Surp Yoon ${ }^{1}$, Se Ik $\mathrm{Joo}^{2}$, Yu Yeon Hwang ${ }^{4}$, Keonhan $\mathrm{Kim}^{6}$, In Ho Jang ${ }^{10}$, and Jin $\mathrm{Heo}^{11}$, as Clinical Microbiology Subcommitte, The Korean Association of Quality Assurance for Clinical Laboratory

${ }^{1}$ Department of Laboratory Medicine, Asan Medical Center, University of Ulsan College of Medicine; ${ }^{2}$ Department of Laboratory Medicine, Seoul National University Hospital, Seoul National University College of Medicine, Seoul; ${ }^{3}$ Department of Laboratory Medicine, Chonnam National University Hospital, Chonnam National University, Gwangju; ${ }^{4}$ Department of Laboratory Medicine, Samsung Medical Center, Sungkyunkwan University

School of Medicine, Seoul; ${ }^{5}$ Department of Laboratory Medicine, Gyeongsang National University Hospital, Gyeongsang National University School of Medicine, Jinju; ${ }^{6}$ Department of Laboratory Medicine, Gangnam Severance Hospital, Yonsei University College of Medicine; ${ }^{7}$ Department of Laboratory Medicine, Hallym University Kangdong Sacred Heart Hospital, Hallym University College of Medicine, Seoul; ${ }^{8}$ Department of Laboratory Medicine, Korean Institute of Tuberculosis, Cheongju, ${ }^{9}$ Department of Laboratory Medicine, Greencross Reference Laboratory; ${ }^{10}$ Department of Laboratory Medicine, Wonju Severance Christian Hospital, Yonsei University Wonju College of Medicine, Wonju;

${ }^{11}$ Department of Laboratory Medicine, Korea University Ansan Hospital, Korea University College of Medicine, Ansan, Korea

Corresponding author:

Mi-Na Kim

Department of Laboratory Medicine,

Asan Medical Center, University of Ulsan

College of Medicine, 88 Olympic-ro 43-gil,

Songpa-gu, Seoul 138-736, Korea

Tel: + +82-2-3010-4511

Fax: $+82-2-478-0884$

E-mail: mnkim@amc.seoul.kr

pISSN: 1225-097X

elSSN: 2288-7261
Annual external quality assessment was performed three times for clinical microbiology division of The Korean Association of Quality Assurance for Clinical Laboratory. For each trial, three sets composed of different combinations of four bacteria and one yeast were distributed for culture, identification, and antimicrobial susceptibility tests. A total of 340 laboratories were enrolled and 330 (97.0\%), 331(97.4\%), and 331(97.4\%) returned the results on trial I, II, and III, respectively. For bacterial identification, the correct identification of gram-negative bacilli, Staphylococcus aureus, Staphylococcus epidermidis, Staphylococcus capitis, Streptococcus agalactiae, Listeria monocytogenes, and Candida species was greater than 95\%. However, correct identification of Staphylococcus lugdunensis, Corynebacterium striatum, Vibrio vulnificus, Aeromonas hydrophila, Cryptococcus neoformans, and Malassezia pachydermatis was relatively less accurate, with values of $95.4 \%, 89.9 \%, 50.7 \%, 91.3 \%, 93.6 \%$, and $93.9 \%$, respectively. Surveillance cultures for vancomycin-resistant enterococci and methicillin-resistant $S$. aureus were correctly determined by $95.4 \%$ and $93.9 \%$ of the respondents, respectively. False carbapenem-resistance due to AmpC $\beta$-lactamase, disk diffusion testing for vancomycin in Staphylococcus species, oxacillin and penicillin susceptibility testing in S. lugdunensis and false imipenem-resistance in Proteus species were common sources of inaccurate results. The accuracy of species identification for Corynebacterium species and Vibrio species requires improvement. Consistent problems occurred with antimicrobial susceptibility testing of vancomycin for Staphylococcus species using the disk diffusion method.

(J Lab Med Qual Assur 2014;36:122-139)

Key Words : External quality assessment, Clinical laboratory, Bacterial culture, Antimicrobial susceptibility test 


\section{Journal of LABORATORY MEDICINE and QUALITY ASSURANCE}

\section{Young Jin Ko et al • External Quality Assessment for Bacterial Culture}

\section{서론}

세균배양동정과 감수성검사의 신빙도조사는 임상미생물학 검사실의 질향상과 유지를 위해 가장 중요한 분야이다. 미국의 College of American Pathologist, 영국의 United Kingdom National External Quality Assessment Scheme 등의 대표 적인 국제 신빙도조사기구에서 각국의 검사실 세균배양동정 과 감수성검사의 신빙도조사를 시행하고 있을 뿐 아니라 항균 제내성전파를 방지하기 위해 세계보건기구에서도 WHONET 에 참여하는 전 세계 검사실을 대상으로 항균제감수성검사의 신빙도조사를 실시하고 있다[1-3]. 최근 세계적인 표준화기구 에서는 항균제내성균의 새로운 출현과 확산으로 이를 검출하 기 위한 감수성검사의 판독기준과 특이적인 검사법이 매년 업 데이트하고 있어서[4-6] 세계적인 경향에 맞추어 국내 검사 실의 지속적인 질향상이 필요하다. 이에 2013년 신빙도조사 는 항균제내성이 문제가 되는 그람음성 막대균과 그람양성 알 균의 항균제감수성검사 신빙도조사를 집중적으로 평가하고자 했으며, 항균제내성균 감시배양검사를 적용해서 임상미생물 검사실에 새롭게 요구되는 검사들의 수행능을 파악하고, 검사 실 질향상을 도모하였다.

\section{재료 및 방법}

\section{1. 신빙도조사 방법}

2013년 신빙도조사사업은 3, 6, 9월에 걸쳐 3회 검체를 발송 했으며, 일반세균의 배양, 동정, 감수성검사, 효모균의 배양과 동정을 모든 참여기관에 배부하였다. 각 검체는 임상 검체에 가상하여 가상환자의 임상적인 배경을 제시하였고, 다양한 검 체와 임상상황을 조건으로 임상적으로 의미 있는 수준의 배양 과 동정을 하도록 요구하였다. 항균제감수성검사 또한 균종과 검체에 따라 적절하게 선택하고, 판독하는지 검증하고자 하였 다. 각 차수에 일반세균검사 분야는 기관별로 다섯 가지의 균 주를 한 세트로 배부하였으며, 3가지 세트를 준비하여 한 세트 가 참여기관 삼분의 일 정도씩 배부되도록 무작위로 배정하였 다. 특수세균 분야는 배양과 동정이 까다로운 세균, 혐기성 세 균, 미호기성 세균, 사상형 진균 등 난이도가 높은 균주를 각 차수별로 2 개씩 구성하여 참여를 신청한 기관에 배부하였다.

\section{2. 관리물질}

1차는 M1301(조직), M1302(혈액), M1303(기관지흡인액), M1304(중심정맥관팁), M1305(대변, vancomycin-resistant enterococci [VRE] 감시배양) 등 5개의 검체를 가상하여 7개
의 균종으로 3 가지 세트를, 2차는 M1311(인공기도 흡인액), M1312(혈액), M1313(뇌척수액), M1314(대변), M1315(창 상, methicillin-resistant Staphylococcus aureus [MRSA] 감시배양) 등 5 개의 검체를 가상하여 7 개의 균종으로 3 가 지 세트를 조합하였고(Table 1), 3차에서는 M1321(혈액), M1322(복수), M1323(뇌척수액), M1324(창상), M1325(객 담) 등 5 개의 검체를 7 종의 균종으로 3 세트를 만들었다(Table 1). 모든 시도에서 5 개의 일반배양 검체는 배양 및 동정을 실 시하고, 각 회차의 앞 번호 두 개의 검체에 대해 항균제감수성 검사를 같이 실시하도록 하였다(Table 1). 모든 세균과 진균은 서울아산병원 진단검사의학과에서 배양된 임상분리주들이었 다. 세균은 혈액 한천배지 또는 쵸콜렛 한천배지에 키우고, 진 균은 SDA (sialodacryoadenitis virus) 한천배지에 키워서 얻 은 집락을 배부하여 검사하도록 하였다. 모든 검체는 운송을 위해 COPAN Amies Transport Swab (COPAN, Brescia, Italy) 배지에 담아 운송하였다. 감염성 검체의 안전한 운송과 생존능 보존을 위해 모든 검체는 녹십자임상검사센터와 서울 임상검사센터와 계약해서 두 검사센터의 임상 검체 배송시스 템을 통해 전국 참여기관에 다음날까지 배송하도록 하였다.

\section{3. 결과 판정기준과 평가}

검체를 배부할 때 검체 종류, 검사항목, 결과 판정기준을 제 시하였다. 균종동정은 종수준까지 맞는 경우를 '우수(good)' 로, 임상적으로 속수준의 동정이 의미가 있다면 속수준까 지 맞는 경우를 '적절(acceptable)'하다고 판정하였다. 이 기 준에 맞지 않은 답을 하거나 답하지 않은 경우 '부적절(not acceptable)'로 판정하였다. 항균제감수성검사는 균종별로 2013년 Clinical and Laboratory Standards Institute (CLSI) M100-S23의 기준[6]에 따라 판정했으며, 가상 검체의 종류에 따라 기준을 달리 적용하여 해석하였다. 감수성검사결과 판독 이 틀린 경우와 필수적인 항균제에 대해 검사하지 않았거나 보 고하지 않도록 권하는 항균제를 결과에 포함시킨 경우 각 0.5 점씩 감점하였다. 균배양검사를 하지 않거나 배양에 실패한 경 우는 감수성검사 배정점수를 총점에서 제외하였다. 동정검사 는 각 8 점, 항균제감수성검사는 두 검체에 대해서 각 20 점을 기준으로 하였다.

\section{결과}

2013년 임상미생물학분과 참여기관은 340기관이었고, 이 중 1차에서 330기관(97.0\%), 2차에서 331기관(97.4\%), 3 차에서 331 기관(97.4\%)이 회신하였다. 3 차례의 조사 중 


\section{Journal of LABORATORY MEDICINE and QUALITY ASSURANCE}

Young Jin Ko et al • External Quality Assessment for Bacterial Culture

Table 1. Performance of species identification

\begin{tabular}{|c|c|c|c|c|}
\hline \multirow{2}{*}{ Variable } & \multirow{2}{*}{ Organism } & \multicolumn{3}{|l|}{ Species identification } \\
\hline & & Species identification & Criteria & Value \\
\hline \multirow[t]{7}{*}{ M1301 } & E. cloacae & Enterobacter cloacae & G & $171(86.8)$ \\
\hline & & Enterobacter aerogenes & A & $1(0.5)$ \\
\hline & & Enterobacter asburiae & A & $1(0.5)$ \\
\hline & & Others & NA & $2(1.0)$ \\
\hline & E. coli & Escherichia coli & G & $84(65.1)$ \\
\hline & & Others & NA & $2(1.6)$ \\
\hline & & No response & - & $43(33.3)$ \\
\hline \multirow[t]{10}{*}{ M1302 } & S. lugdunensis & Staphylococcus lugdunensis & G & $226(69.3)$ \\
\hline & & Staphylococcus, coagulase negative & A & $14(4.3)$ \\
\hline & & Staphylococcus species not Staphylococcus aureus & A & $2(0.6)$ \\
\hline & & Staphylococcus haemolyticus & A & $1(0.3)$ \\
\hline & & Staphylococcus hominis & A & $1(0.3)$ \\
\hline & & Staphylococcus simulans & A & $1(0.3)$ \\
\hline & & Staphylococcus species & A & $1(0.3)$ \\
\hline & & Staphylococcus xylosus & A & $1(0.3)$ \\
\hline & & Staphylococcus aureus & NA & $12(3.7)$ \\
\hline & & No response & - & $67(20.6)$ \\
\hline \multirow[t]{7}{*}{ M1303 } & C. striatum & Corynebacterium striatum & G & $147(45.1)$ \\
\hline & & Corynebacterium species & A & $47(14.4)$ \\
\hline & & Unidentified gram-positive rods & A & $16(4.9)$ \\
\hline & & Unidentified gram-positive coccobacilli & A & $3(0.9)$ \\
\hline & & Corynebacterium amycolatum & A & $1(0.3)$ \\
\hline & & Others & NA & $24(7.3)$ \\
\hline & & No response & - & $88(27.0)$ \\
\hline \multirow[t]{10}{*}{ M1304 } & M. pachydermatis & Malassezia pachydermatis & G & $72(87.8)$ \\
\hline & & Malassezia furfur complex & A & $3(3.7)$ \\
\hline & & Yeast like organism & A & $2(2.4)$ \\
\hline & & Others & NA & $5(6.1)$ \\
\hline & C. glabrata & Candida glabrata & G & $116(47.5)$ \\
\hline & & Yeast-like organism & A & $23(9.4)$ \\
\hline & & Candida species & A & $17(7.0)$ \\
\hline & & Candida species not C. albicans & A & $8(3.3)$ \\
\hline & & Others & NA & $3(1.2)$ \\
\hline & & No response & - & $77(31.6)$ \\
\hline \multirow[t]{3}{*}{ M1305 } & Enterococcus faecium & VRE isolated & G & $246(75.5)$ \\
\hline & & Others & NA & $12(3.4)$ \\
\hline & & No response & - & $68(20.9)$ \\
\hline
\end{tabular}

(Continued to the next page) 
Journal of LABORATORY MEDICINE and QUALITY ASSURANCE

Young Jin Ko et al • External Quality Assessment for Bacterial Culture

Table 1. Continued

\begin{tabular}{|c|c|c|c|c|}
\hline \multirow{2}{*}{ Variable } & \multirow{2}{*}{ Organism } & \multicolumn{3}{|c|}{ Species identification } \\
\hline & & Species identification & Criteria & Value \\
\hline \multirow[t]{5}{*}{ M1311 } & P. aeruginosa & Pseudomonas aeruginosa & G & $193(88.9)$ \\
\hline & & No response & NA & $24(11.1)$ \\
\hline & S. maltophilia & Stenotrophomonas maltophilia & G & $67(58.8)$ \\
\hline & & Others & NA & $3(2.6)$ \\
\hline & & No response & - & $44(38.6)$ \\
\hline \multirow[t]{9}{*}{ M1312 } & S. capitis & Staphylococcus capitis & G & $112(33.8)$ \\
\hline & & Staphylococcus capitis subspecies capitis & A & $88(26.6)$ \\
\hline & & Staphylococcus capitis subspecies urealyticus & A & $28(8.5)$ \\
\hline & & Staphylococcus, coagulase negative & A & $24(7.3)$ \\
\hline & & Staphylococcus epidermidis & A & $8(2.4)$ \\
\hline & & Staphylococcus saccharolyticus & A & $1(0.3)$ \\
\hline & & Staphylococcus species not Staphylococcus aureus & A & $1(0.3)$ \\
\hline & & Staphylococcus aureus & NA & $1(0.3)$ \\
\hline & & No response & - & $68(20.5)$ \\
\hline \multirow[t]{10}{*}{ M1313 } & S. agalactiae & Streptococcus agalactiae & G & $157(74.1)$ \\
\hline & & Streptococcus, beta-hemolytic group B & G & $2(0.9)$ \\
\hline & & Others & NA & $6(3.0)$ \\
\hline & & No response & - & $47(22.2)$ \\
\hline & L. monocytogenes & Listeria monocytogenes & G & $79(66.4)$ \\
\hline & & Unidentified gram-positive rods & A & $3(2.5)$ \\
\hline & & Listeria species & A & $2(1.7)$ \\
\hline & & Unidentified gram-positive coccobacilli & A & $1(0.8)$ \\
\hline & & Others & NA & $7(5.9)$ \\
\hline & & No response & - & $27(22.7)$ \\
\hline \multirow[t]{9}{*}{ M1314 } & V. cholera non-O1 & Vibrio cholerae non-O1 & G & $60(27.6)$ \\
\hline & & Vibrio cholerae & G & $130(59.9)$ \\
\hline & & Vibrio species & A & $2(0.9)$ \\
\hline & & Vibrio vulnificus & NA & $1(0.5)$ \\
\hline & & No response & - & $24(11.1)$ \\
\hline & V. vulnificus & Vibrio vulnificus & G & $34(29.8)$ \\
\hline & & Vibrio species & A & $1(0.9)$ \\
\hline & & Others & NA & $34(29.8)$ \\
\hline & & No response & - & $45(39.5)$ \\
\hline \multirow[t]{3}{*}{ M1315 } & MRSA isolated & MRSA isolated & G & $247(74.6)$ \\
\hline & & Others & NA & $16(4.8)$ \\
\hline & & No response & - & $68(20.5)$ \\
\hline \multirow[t]{4}{*}{ M1321 } & S. aureus & Staphylococcus aureus & G & $143(61.4)$ \\
\hline & & MRSA isolated & A & $16(6.9)$ \\
\hline & & Staphylococcus epidermidis & NA & $4(1.7)$ \\
\hline & & No response & - & $70(30.0)$ \\
\hline
\end{tabular}

(Continued to the next page) 


\section{Journal of LABORATORY MEDICINE and QUALITY ASSURANCE}

Young Jin Ko et al • External Quality Assessment for Bacterial Culture

Table 1. Continued

\begin{tabular}{|c|c|c|c|c|}
\hline \multirow{2}{*}{ Variable } & \multirow{2}{*}{ Organism } & \multicolumn{3}{|c|}{ Species identification } \\
\hline & & Species identification & Criteria & Value \\
\hline & S. epidermidis & Staphylococcus epidermidis & $\mathrm{G}$ & $97(99.0)$ \\
\hline & & Staphylococcus, coagulase negative & A & $1(1.0)$ \\
\hline \multirow[t]{5}{*}{ M1322 } & P. penneri & Proteus penneri & G & $193(58.3)$ \\
\hline & & Proteus vulgaris & A & $59(17.8)$ \\
\hline & & Proteus species & A & $8(2.4)$ \\
\hline & & Proteus mirabilis & A & $1(0.3)$ \\
\hline & & No response & - & $70(21.1)$ \\
\hline \multirow[t]{8}{*}{ M1323 } & H. influenzae & Haemophilus influenzae & G & $207(62.5)$ \\
\hline & & Haemophilus influenzae, not type B & G & $3(0.9)$ \\
\hline & & Haemophilus influenzae (type B) & G & $3(0.9)$ \\
\hline & & Haemophilus species & A & $15(4.5)$ \\
\hline & & Unidentified gram-negative rods & A & $2(0.6)$ \\
\hline & & Unidentified gram-negative coccobacilli & A & $2(0.6)$ \\
\hline & & Others & NA & $15(4.5)$ \\
\hline & & No response & - & $84(25.4)$ \\
\hline \multirow[t]{14}{*}{ M1324 } & V. alginolyticus & Vibrio alginolyticus & G & $176(81.1)$ \\
\hline & & Vibrio species & A & $6(2.8)$ \\
\hline & & Vibrio vulnificus & A & $3(1.4)$ \\
\hline & & Unidentified gram-negative rods & $\mathrm{A}$ & $1(0.5)$ \\
\hline & & Others & NA & $6(2.8)$ \\
\hline & & No response & - & $25(11.5)$ \\
\hline & A. hydrophila & Aeromonas hydrophila & G & $54(47.4)$ \\
\hline & & $\begin{array}{l}\text { Aeromonas hydrophila complex (A. bestirarum, } \\
\text { A. hydrophila, A. salmonicida) }\end{array}$ & G & $3(2.6)$ \\
\hline & & Aeromonas caviae & A & $2(1.8)$ \\
\hline & & Aeromonas species & A & $2(1.8)$ \\
\hline & & Aeromonas sobria & A & $1(0.9)$ \\
\hline & & Aeromonas veronii & $\mathrm{A}$ & $1(0.9)$ \\
\hline & & Others & NA & $6(5.3)$ \\
\hline & & No response & - & $45(39.5)$ \\
\hline \multirow[t]{5}{*}{ M1325 } & C. neoformans & Cryptococcus neoformans & G & $209(63.1)$ \\
\hline & & Cryptococcus species & A & $6(1.8)$ \\
\hline & & Yeast like organism & A & $21(6.3)$ \\
\hline & & Others & NA & $16(4.8)$ \\
\hline & & No response & - & $79(23.9)$ \\
\hline
\end{tabular}

Values are presented as laboratories's number (\%).

Abbreviations: G, good; A, acceptable; NA, not acceptable.

Haemophilus influenzae의 균배양에 실패한 기관이 5 군데였 던 것을 제외하면 비교적 까다로운 세균의 생존능도 잘 보존되
었다. 다른 검체도 균배양 실패는 매우 드물어서 실패가 있었 던 검체도 대부분 1-3곳에 불과하였다. 


\section{Journal of LABORATORY MEDICINE and QUALITY ASSURANCE}

\section{Young Jin Ko et al • External Quality Assessment for Bacterial Culture}

\section{1. 동정검사결과}

1차에 시도한 장내세균인 Enterobacter cloacae, Escherichia coli의 acceptable\% (good\%)는 98.9 (97.7), 97.7 (97.7)로 종수준의 동정까지 정확한 우수한 동정능력을 보 였다(Table 1). 이에 비해 Staphylococcus lugdunensis, Corynebacterium striatum, Candida glabrata, Malassezia pachydermatis는 95.4 (87.3), 89.9 (61.7), 98.2 (69.4), 93.9 (87.8)로 acceptable\%가 더 낮았고, 특히 종수준 동정 정확 도는 훨씬 떨어졌다. S. lugdunensis의 동정 정확도는 종수 준 $69.3 \%$ 로 낮았고, Staphylococcus aureus로 보고한 기관 이 12 곳(4.6\%)이 있어서 acceptable\%가 $95.4 \%$ 로 떨어지는 데 절대적으로 기여했다. 이는 S. lugdunensis가 clumping factor가 양성이기 때문에 coagulase를 검출하는 라텍스응
집법검사로 S. aureus를 동정하는 기관들에서 발생하였다. 2차에서 Pseudomonas aeruginosa, Stenotrophomonas maltophilia, S. capitis, Streptococcus agalactiae, Listeria monocytogenes, Vibrio cholerae, $V$. vulnificus의 동정 정확 도는 acceptable\% (good\%)가 100.0 (100.0), 95.7 (95.7), 99.6 (87.0), 96.4 (96.4), 92.4 (85.9), 99.4 (98.4), 50.7 (49.3)로 P. aeruginosa, Vibrio cholerae는 종수준까지 정 확한 우수한 동정능력을 보였다. 이에 비해 S. capitis, L. monocytogenes는 종수준 동정 정확도가 낮았다(Table 1). V. vulnificus의 acceptable\%가 $50 \%$ 대로 낮았는데 이는 $36 \%$ 의 기관이 대변 검체의 정상상재균으로 섞인 E. coli를 동정하여 보고하였기 때문이었다. 3차에서 S. aureus, S. epidermidis, Proteus penneri, $H$. influenzae, V. alginolyticus, Aero-

Table 2. Performance of antimicrobial susceptibility test for M1301 Enterobacter cloacae

\begin{tabular}{|c|c|c|c|c|c|c|c|c|c|c|c|c|}
\hline \multirow{2}{*}{ Antimicrobials } & \multicolumn{6}{|c|}{ Disk diffusion method } & \multicolumn{6}{|c|}{ Commercial broth dilution method } \\
\hline & Total & $S$ & I & $\mathbf{R}$ & Criteria & $\%$ & Total & $S$ & I & $\mathrm{R}$ & Criteria & $\%$ \\
\hline Amikacin & 19 & 18 & - & 1 & S & 94.7 & 119 & 118 & - & 1 & S & 99.2 \\
\hline Amoxicillin/Cla & 6 & - & - & 6 & $\mathrm{R}$ & 100.0 & 78 & - & - & 78 & $\mathrm{R}$ & 100.0 \\
\hline Ampicillin & 14 & - & - & 14 & $\mathrm{R}$ & 100.0 & 136 & - & - & 136 & $\mathrm{R}$ & 100.0 \\
\hline Ampicillin/Sul & 7 & - & - & 7 & $\mathrm{R}$ & 100.0 & 15 & - & - & 15 & $\mathrm{R}$ & 100.0 \\
\hline Aztreonam & 3 & - & - & 3 & $\mathrm{R}$ & 100.0 & 21 & - & - & 21 & $\mathrm{R}$ & 100.0 \\
\hline Cefazolin & 6 & - & - & 6 & $\mathrm{R}$ & 100.0 & 127 & - & - & 127 & $\mathrm{R}$ & 100.0 \\
\hline Cefepime & 5 & 5 & - & - & S & 100.0 & 123 & 122 & - & 1 & S & 99.2 \\
\hline Cefotaxime & 10 & - & - & 10 & $\mathrm{R}$ & 100.0 & 120 & - & - & 120 & $\mathrm{R}$ & 100.0 \\
\hline Cefotetan & 3 & - & - & 3 & $\mathrm{R}$ & 100.0 & 5 & - & - & 5 & $\mathrm{R}$ & 100.0 \\
\hline Cefoxitin & 4 & - & - & 4 & $\mathrm{R}$ & 100.0 & 74 & - & - & 74 & $\mathrm{R}$ & 100.0 \\
\hline Ceftazidime & 8 & - & - & 8 & $\mathrm{R}$ & 100.0 & 20 & - & - & 20 & $\mathrm{R}$ & 100.0 \\
\hline Ceftriaxone & 9 & - & 1 & 8 & $\mathrm{R}$ & 100.0 & 4 & - & - & 4 & $\mathrm{R}$ & 100.0 \\
\hline Cefuroxime & 4 & - & - & 4 & $\mathrm{R}$ & 100.0 & 3 & - & - & 3 & $\mathrm{R}$ & 100.0 \\
\hline Ciprofloxacin & 18 & 14 & 4 & - & S & 77.8 & 123 & 120 & 2 & 1 & S & 97.6 \\
\hline Ertapenem & - & - & - & - & - & - & 51 & 38 & 1 & 12 & $\mathrm{~S} / \mathrm{I} / \mathrm{R}$ & - \\
\hline Gentamicin & 17 & 17 & - & - & S & 100.0 & 149 & 148 & - & 1 & S & 99.3 \\
\hline Imipenem & 16 & 15 & 1 & - & S & 93.8 & 113 & 107 & 5 & 1 & S & 94.7 \\
\hline Levofloxacin & 3 & 2 & 1 & - & S & 66.7 & 16 & 16 & - & - & S & 100.0 \\
\hline Meropenem & 5 & 5 & - & - & S & 100.0 & 16 & 16 & - & - & S & 100.0 \\
\hline Piperacillin & 6 & 1 & 1 & 4 & $\mathrm{R}$ & 66.7 & 7 & - & - & 7 & $\mathrm{R}$ & 100.0 \\
\hline Piperacillin/Taz & 2 & - & - & 2 & $\mathrm{R}$ & 100.0 & 39 & - & 2 & 37 & $\mathrm{R}$ & 94.9 \\
\hline Tobramycin & 8 & 8 & - & - & S & 100.0 & 27 & 27 & - & - & S & 100.0 \\
\hline TMP-SMX & 13 & 13 & - & - & S & 100.0 & 110 & 110 & - & - & S & 100.0 \\
\hline Tigecycline & - & - & - & - & - & - & 4 & 4 & - & - & - & - \\
\hline
\end{tabular}

Abbreviations: S, susceptible; I, intermediate; R, resistance; Amoxicillin/Cla, amoxicillin/clavulanic acid; Ampicillin/Sul, ampicillin/sulbactam; Cefoperazone/Sul, cefoperazone/sulbactam; Piperacillin/Taz, piperacillin/tazobactam; TMP-SMX, trimethoprim-sulfamethoxazole. 


\section{Journal of LABORATORY MEDICINE and QUALITY ASSURANCE}

\section{Young Jin Ko et al • External Quality Assessment for Bacterial Culture}

monas hydrophila, Cryptococcus neoformans 동정 정확도 는 acceptable\% (good\%)가 97.5 (87.7), 100.0 (99.0), 100.0 (73.9), 96.9 (91.3), 96.8 (91.7), 91.3 (82.6), 93.6 (82.9)로 S. epidermidis만 종수준까지 정확한 우수한 동정능력을 보 였다(Table 1). 이에 비해 S. aureus의 종수준 동정 정확도가 낮은 이유는 MRSA isolated로 보고한 기관이 있었기 때문이 고, C. neoformans의 경우 진균동정을 하지 않는 기관이 많 기 때문에 good\%가 낮았다. P. penneri, A. hydrophila 속수 준까지만 맞는 기관이 다수 있어서 이들 균종의 종동정이 취 약하였다. P. penneri를 P. vulgaris로 보고한 기관들의 동정 장비는 VITEK2 (bioMerieux SA, Marcy l’Etoile, France), MicroScan (Siemens, Sacramento, CA, USA), Phoenix (Becton Dickinson, Sparks, MD, USA) 등 고루 분포하고
있어서 상품화된 동정제품들이 두 균종을 잘 감별하지 못하였 다.

\section{2. 감시배양검사와 특수세균검사}

항균제내성균 감시배양검사의 질관리를 위해 1 차에 $\mathrm{VRE}$ 감시배양, 2차에 MRSA 감시배양을 요청하였는데 M1305 검체는 반코마이신 내성 장구균의 감시배양은 응답기관 중 $95.4 \%$ 가 정확한 답을 하였고, Enterococcus faecium이라고 입력한 기관은 8곳에 불과하여, 2012년 M1225 검체에 대해 VRE not isolated로 적절한 답이 $63.5 \%$ 로 $30 \%$ 는 균동정만 을 입력하였던 것에 비해 많이 개선되었다. M1315 MRSA 감 시배양 검체는 MRSA isolated로 $93.9 \%$ 가 정확한 답을 하였 으나, S. aureus라고 답한 기관이 14 곳이 있어서 감시배양검

Table 3. Performance of antimicrobial susceptibility test for M1301 Escherichia coli

\begin{tabular}{|c|c|c|c|c|c|c|c|c|c|c|c|c|}
\hline \multirow{2}{*}{ Antimicrobials } & \multicolumn{6}{|c|}{ Disk diffusion method } & \multicolumn{6}{|c|}{ Commercial broth dilution method } \\
\hline & Total & S & I & $\mathbf{R}$ & Criteria & $\%$ & Total & $S$ & I & $\mathrm{R}$ & Criteria & $\%$ \\
\hline Amikacin & 26 & 25 & 1 & - & $S$ & 96.2 & 47 & 46 & 1 & - & $S$ & 97.9 \\
\hline Amoxicillin/Cla & 10 & - & - & 10 & $\mathrm{R}$ & 100.0 & 27 & - & - & 27 & $\mathrm{R}$ & 100.0 \\
\hline Ampicillin & 24 & - & - & 24 & $\mathrm{R}$ & 100.0 & 49 & - & - & 49 & $\mathrm{R}$ & 100.0 \\
\hline Ampicillin/Sul & 7 & - & - & 7 & $\mathrm{R}$ & 100.0 & 6 & - & - & 6 & $\mathrm{R}$ & 100.0 \\
\hline Aztreonam & 9 & 1 & - & 8 & $\mathrm{R}$ & 88.9 & 11 & - & 1 & 10 & $\mathrm{R}$ & 90.9 \\
\hline Cefazolin & 4 & - & - & 4 & $\mathrm{R}$ & 100.0 & 46 & - & - & 46 & $\mathrm{R}$ & 100.0 \\
\hline Cefepime & 2 & 2 & - & - & S & 100.0 & 36 & 7 & 1 & 28 & S & 19.4 \\
\hline Cefotaxime & 17 & - & 1 & 16 & $\mathrm{R}$ & 94.1 & 42 & - & 3 & 39 & $\mathrm{R}$ & 92.9 \\
\hline Cefotetan & 2 & - & - & 2 & $\mathrm{R}$ & 100.0 & 4 & - & - & 4 & $\mathrm{R}$ & 100.0 \\
\hline Cefoxitin & 2 & - & - & 2 & $\mathrm{R}$ & 100.0 & 24 & - & - & 24 & $\mathrm{R}$ & 100.0 \\
\hline Ceftazidime & 10 & 1 & - & 9 & $\mathrm{R}$ & 90.0 & 4 & - & - & 4 & $\mathrm{R}$ & 100.0 \\
\hline Ceftriaxone & 13 & 2 & - & 11 & $\mathrm{R}$ & 84.6 & 1 & - & - & 1 & $\mathrm{R}$ & 100.0 \\
\hline Cephalothin & 6 & - & - & 6 & $\mathrm{R}$ & 100.0 & - & - & - & - & - & - \\
\hline Ciprofloxacin & 24 & 1 & - & 23 & $\mathrm{R}$ & 95.8 & 40 & - & - & 40 & $\mathrm{R}$ & 100.0 \\
\hline Ertapenem & - & - & - & - & - & - & 11 & 1 & 1 & 9 & $\mathrm{I} / \mathrm{R}$ & 90.9 \\
\hline Gentamicin & 25 & 4 & - & 21 & $\mathrm{R}$ & 84.0 & 50 & - & - & 50 & $\mathrm{R}$ & 100.0 \\
\hline Imipenem & 22 & 21 & - & 1 & S & 95.5 & 40 & 34 & - & 6 & S & 85.0 \\
\hline Levofloxacin & 4 & 1 & - & 3 & $\mathrm{R}$ & 75.0 & 6 & - & - & 6 & $\mathrm{R}$ & 100.0 \\
\hline Meropenem & 7 & 7 & - & & S & 100.0 & 8 & 8 & - & - & $\mathrm{S}$ & 100.0 \\
\hline Piperacillin & 9 & 1 & 1 & 7 & $\mathrm{R}$ & 77.8 & 6 & - & - & 6 & $\mathrm{R}$ & 100.0 \\
\hline Piperacillin/Taz & 2 & - & 1 & 1 & $\mathrm{I} / \mathrm{R}$ & 100.0 & 12 & - & 3 & 9 & $\mathrm{I} / \mathrm{R}$ & 100.0 \\
\hline TMP-SMX & 16 & 1 & - & 15 & $\mathrm{R}$ & 93.8 & 28 & - & - & 28 & $\mathrm{R}$ & 100.0 \\
\hline Tobramycin & 7 & 1 & 1 & 5 & $\mathrm{R}$ & 71.4 & 11 & - & - & 11 & $\mathrm{R}$ & 100.0 \\
\hline
\end{tabular}

Abbreviations: S, susceptible; I, intermediate; R, resistance; Amoxicillin/Cla, amoxicillin/clavulanic acid; Ampicillin/Sul, ampicillin/sulbactam; Piperacillin/Taz, piperacillin/tazobactam; TMP-SMX, trimethoprim-sulfamethoxazole. 


\section{Journal of LABORATORY MEDICINE and QUALITY ASSURANCE}

Young Jin Ko et al • External Quality Assessment for Bacterial Culture

사 목적에 맞는 수준의 동정을 하도록 더 개선할 필요가 있었 다. 특수세균에 대해 66기관이 신빙도조사에 참여하였다. 속 수준까지 동정 정확도는 1차에 S1301는 위막성장염이 의심되 는 환자에서 Clostridium difficile 독소검사를 하기를 요청했 는데도 이 중 C. difficile toxin 양성으로 보고한 기관은 $53 \%$ 에 불과하였다. $37 \%$ 인 24 기관이 배양에서 C. difficile 동정결 과만 보고하여 기대했던 결과와 일치하지 않았다. 이는 독소검 사를 하는 최초의 시도였기 때문에 부적절한 답을 한 기관이 많았던 것으로 생각되었다. S1302는 Gardrenella vaginalis
보다 Bifidobacterium으로 보고한 기관이 많아서 기대값을 보 고한 기관은 $40 \%$ 정도에 불과하였다. 이전 논문들을 보면 질 도말의 배양보다는 직접도말 검경으로 Nugent score를 산정 할 때 Bifidobacterium breve가 Gardnerella vaginalis로 오 인되는 것이 문제점으로 지적되어 둘을 감별하기 위한 분자 유전학적 진단방법이 연구되고 있다[7]. 2차에서 혐기성세균 인 S1303 검체는 94.3\%가 C. perfringenes로 종수준까지 정 확히 동정하였고, 털곰팡이균의 동정을 목적으로 한 M1304 는 Trichophyton rubrum이 기대값이었는데 Trichosporon

Table 4. Performance of antimicrobial susceptibility test for M1322 Proteus penneri

\begin{tabular}{|c|c|c|c|c|c|c|c|c|c|c|c|c|}
\hline \multirow{2}{*}{ Antimicrobials } & \multicolumn{6}{|c|}{ Disk diffusion method } & \multicolumn{6}{|c|}{ Commercial broth dilution method } \\
\hline & Total & $S$ & I & $\mathrm{R}$ & Criteria & $\%$ & Total & $S$ & I & $\mathrm{R}$ & Criteria & $\%$ \\
\hline Amikacin & 40 & 40 & - & - & $S$ & 100.0 & 166 & 166 & - & - & $S$ & 100.0 \\
\hline Amoxicillin/Cla & 15 & 13 & - & 2 & S & 86.7 & 106 & 101 & 4 & 1 & $S$ & 95.3 \\
\hline Ampicillin & 37 & - & - & 37 & $\mathrm{R}$ & 100.0 & 198 & - & - & 198 & $\mathrm{R}$ & 100.0 \\
\hline Ampicillin/Sul & 13 & 13 & - & - & $S$ & 100.0 & 9 & 8 & 1 & - & $S$ & 88.9 \\
\hline Aztreonam & 10 & 10 & - & - & S & 100.0 & 26 & 25 & - & 1 & S & 96.2 \\
\hline Cefazolin & 12 & - & - & 12 & $\mathrm{R}$ & 100.0 & 185 & 1 & - & 184 & $\mathrm{R}$ & 99.5 \\
\hline Cefepime & 6 & - & - & 6 & S & 100.0 & 176 & 175 & - & 1 & S & 99.4 \\
\hline Cefotaxime & 26 & 26 & - & - & S & 100.0 & 143 & 135 & 3 & 5 & S & 94.4 \\
\hline Cefoxitin & 5 & 5 & - & - & S & 100.0 & 114 & 113 & - & 1 & S & 99.1 \\
\hline Ceftazidime & 20 & 19 & - & 1 & S & 95.0 & 23 & 23 & - & - & S & 100.0 \\
\hline Ceftriaxone & 19 & 18 & - & 1 & S & 94.7 & 5 & 3 & - & 2 & S & 60.0 \\
\hline Cephalothin & 11 & - & - & 11 & $\mathrm{R}$ & 100.0 & 1 & - & - & 1 & $\mathrm{R}$ & 100.0 \\
\hline Ciprofloxacin & 43 & 43 & - & - & S & 100.0 & 164 & 164 & - & - & S & 100.0 \\
\hline Ertapenem & - & - & - & - & - & - & 97 & 97 & - & - & S & 100.0 \\
\hline Gentamicin & 41 & 41 & - & - & S & 100.0 & 198 & 198 & - & - & S & 100.0 \\
\hline Imipenem & 41 & 36 & 1 & 4 & - & 87.8 & 94 & 59 & 25 & 10 & - & 62.8 \\
\hline Levofloxacin & 8 & 8 & - & - & S & 100.0 & 19 & 19 & - & - & S & 100.0 \\
\hline Meropenem & 13 & 13 & - & - & S & 100.0 & 37 & 37 & - & - & S & 100.0 \\
\hline Piperacillin & 15 & 14 & 1 & - & S & 93.3 & 18 & 15 & 2 & 1 & S & 83.3 \\
\hline Piperacillin/Taz & 5 & 5 & - & - & S & 100.0 & 81 & 81 & - & - & S & 100.0 \\
\hline Tetracycline & 3 & 3 & - & - & - & - & 2 & 2 & - & - & - & - \\
\hline Ticarcillin & 1 & 1 & - & - & - & - & - & - & - & - & - & - \\
\hline Ticarcillin/Cla & 1 & 1 & - & - & - & - & 8 & 8 & - & - & - & - \\
\hline Tigecycline & - & - & - & - & - & - & 1 & - & - & 1 & IA & - \\
\hline Tobramycin & 14 & 14 & - & - & S & 100.0 & 35 & 35 & - & - & S & 100.0 \\
\hline TMP-SMX & 25 & 25 & - & - & $\mathrm{S}$ & 100.0 & 146 & 146 & - & - & S & 100.0 \\
\hline Vancomycin & 1 & - & - & 1 & IA & - & - & - & - & - & - & - \\
\hline
\end{tabular}

Abbreviations: S, susceptible; I, intermediate; R, resistance; Amoxicillin/Cla, amoxicillin/clavulanic acid; Ampicillin/Sul, ampicillin/sulbactam; Piperacillin/Taz, piperacillin/tazobactam; Ticarcillin/Cla, ticarcillin/clavulanic acid; IA, inappropriate choice of antimicrobials; TMP-SMX, trimethoprim-sulfamethoxazole. 


\section{Journal of LABORATORY MEDICINE and QUALITY ASSURANCE}

\section{Young Jin Ko et al • External Quality Assessment for Bacterial Culture}

의 다른 종을 보고한 기관이 19 곳(28.8\%)으로 종동정 정확 도가 낮았다. 3 차는 참여기관 수가 총 72 기관으로 늘었다. Carbapenem-resistant Enterobacteriaceae (CRE) 감시배 양 검체이었던 S1305는 Serratia marcescens로 100\% 정확 하게 동정하였고, 이 중 46기관이 $\mathrm{CRE}$ 라고 답했다. 혐기성배 양을 요구한 S1306은 65기관(90.3\%)이 Propionibacterium acnes로 정확히 종동정을 하였다.

\section{3. 항균제감수성검사}

M1301의 E. cloacae (Table 2)와 E. coli (Table 3)는 $\mathrm{ACT}-1$ 과 $\mathrm{CMY}$ 계열의 $\mathrm{AmpC} \beta$-lactamase로 인한 광범위 베 타락탐계항생제 내성과 ertapenem 내성이 있었는데 이를 검

Table 5. Performance of antimicrobial susceptibility test for M1302 Staphylococcus lugdunensis

\begin{tabular}{|c|c|c|c|c|c|c|c|c|c|c|c|c|}
\hline \multirow{3}{*}{ Antimicrobials } & \multicolumn{12}{|c|}{ No. of laboratories } \\
\hline & \multicolumn{6}{|c|}{ Disk diffusion method } & \multicolumn{6}{|c|}{ Commercial broth dilution method } \\
\hline & Total & $S$ & I & $\mathrm{R}$ & Criteria & $\%$ & Total & $\mathrm{S}$ & I & $\mathrm{R}$ & Criteria & $\%$ \\
\hline Cefamandole & 1 & 1 & - & - & IA & - & - & - & - & - & - & - \\
\hline Cefazolin & 2 & 2 & - & - & IA & - & 3 & 3 & - & - & IA & - \\
\hline Cefmetazole & 1 & 1 & - & - & IA & - & - & - & - & - & - & - \\
\hline Cefoperazone/Sul & 1 & 1 & - & - & IA & - & - & - & - & - & - & - \\
\hline Cefotaxime & 1 & 1 & - & - & IA & - & 1 & 1 & - & - & IA & - \\
\hline Cefoxitin & 7 & 7 & - & - & - & - & 1 & 1 & - & - & - & - \\
\hline Ceftazidime & 1 & 1 & - & - & IA & - & - & - & - & - & - & - \\
\hline Ceftriaxone & 3 & 3 & - & - & IA & - & - & - & - & - & - & - \\
\hline Cefuroxime axetil & 1 & 1 & - & - & IA & - & - & - & - & - & - & - \\
\hline Cephalothin & 1 & 1 & - & - & IA & - & 2 & 2 & - & - & IA & - \\
\hline Chloramphenicol & 7 & 7 & - & - & S & 100.0 & 5 & 5 & - & - & S & 100.0 \\
\hline Ciprofloxacin & 18 & 18 & - & - & S & 100.0 & 118 & 118 & - & - & S & 100.0 \\
\hline Clindamycin & 16 & 16 & - & - & S & 100.0 & 194 & 194 & - & - & $\mathrm{S}$ & 100.0 \\
\hline Daptomycin & - & - & - & - & - & - & 19 & 19 & - & - & S & 100.0 \\
\hline Erythromycin & 19 & 17 & 1 & 1 & S & 89.5 & 196 & 195 & 1 & - & $\mathrm{S}$ & 99.5 \\
\hline Gentamicin & 17 & 17 & - & - & $S$ & 100.0 & 97 & 96 & - & 1 & S & 100.0 \\
\hline Imipenem & 2 & 2 & - & - & IA & - & 1 & 1 & - & - & IA & - \\
\hline Linezolid & 3 & 3 & - & - & $S$ & 100.0 & 169 & 169 & - & - & S & 100.0 \\
\hline Meropenem & 1 & 1 & - & - & IA & - & - & - & - & - & - & - \\
\hline Nitrofurantoin & - & - & - & - & - & - & 2 & 2 & - & - & Urine only & - \\
\hline Oxacillin & 19 & 13 & 1 & 5 & S & 68.4 & 200 & 154 & - & 46 & S & 77.0 \\
\hline Penicillin G & 19 & 17 & - & 2 & $S$ & 89.5 & 177 & 124 & 2 & 51 & S & 70.1 \\
\hline Quinupristin/Dal & - & - & - & - & - & - & 9 & 9 & - & - & S & 100.0 \\
\hline Rifampin & 3 & 3 & - & - & S & 100.0 & 127 & 127 & - & - & S & 100.0 \\
\hline Teicoplanin & 6 & 6 & - & - & S & 100.0 & 36 & 36 & - & - & $\mathrm{S}$ & 100.0 \\
\hline Telithromycin & - & - & - & - & - & - & 22 & 22 & - & - & $\mathrm{S}$ & 100.0 \\
\hline Tetracycline & 10 & 10 & - & - & S & 100.0 & 182 & 182 & - & - & $\mathrm{S}$ & 100.0 \\
\hline Tigecycline & - & - & - & - & IA & - & 1 & 1 & - & - & IA & - \\
\hline TMP-SMX & 17 & 17 & - & - & S & 100.0 & 187 & 186 & - & 1 & S & 99.5 \\
\hline Vancomycin & 15 & 15 & - & - & MIC only & - & 200 & 200 & - & - & S & 100.0 \\
\hline
\end{tabular}

Abbreviations: S, susceptible; I, intermediate; R, resistance; IA, inappropriate choice of antimicrobials; Cefoperazone/Sul, cefoperazone/ sulbactam; Quinupristin/Dal, quinupristin-dalfopristin; TMP-SMX, trimethoprim-sulfamethoxazole. 


\section{Journal of LABORATORY MEDICINE and QUALITY ASSURANCE}

Young Jin Ko et al • External Quality Assessment for Bacterial Culture

Table 6. Performance of antimicrobial susceptibility test for M1312 Staphylococcus capitis

\begin{tabular}{|c|c|c|c|c|c|c|c|c|c|c|c|c|}
\hline \multirow{2}{*}{ Antimicrobials } & \multicolumn{6}{|c|}{ Disk diffusion method } & \multicolumn{6}{|c|}{ Commercial broth dilution method } \\
\hline & Total & $\mathrm{S}$ & I & $\mathrm{R}$ & Criteria & $\%$ & Total & $\mathrm{S}$ & I & $\mathbf{R}$ & Criteria & $\%$ \\
\hline Amoxicillin/Cla & 1 & 1 & - & - & IA & - & 2 & 2 & - & - & IA & - \\
\hline Ampicillin & 3 & 3 & - & - & IA & - & 6 & 6 & - & - & IA & - \\
\hline Ampicillin/Sul & 1 & 1 & - & - & IA & - & - & - & - & - & - & - \\
\hline Azithromycin & 1 & 1 & - & - & $S$ & 100.0 & 9 & 9 & - & - & S & 100.0 \\
\hline Cefamandole & 2 & 2 & - & - & IA & - & - & - & - & - & - & - \\
\hline Cefazolin & 4 & 4 & - & - & IA & - & 4 & 4 & - & - & IA & - \\
\hline Cefepime & 1 & 1 & - & - & IA & - & 1 & 1 & - & - & IA & - \\
\hline Cefmetazole & 1 & 1 & - & - & IA & - & - & - & - & - & - & - \\
\hline Cefotaxime & 3 & 3 & - & - & IA & - & 2 & 2 & - & - & IA & - \\
\hline Cefoxitin & 7 & 7 & - & - & IA & - & 1 & 1 & - & - & IA & - \\
\hline Ceftazidime & 1 & 1 & - & - & IA & - & - & - & - & - & - & - \\
\hline Ceftriaxone & 5 & 5 & - & - & IA & - & - & - & - & - & - & - \\
\hline Cefuroxime axetil & 1 & 1 & - & - & IA & - & - & - & - & - & - & - \\
\hline Cefuroxime sodium & 2 & 2 & - & - & IA & - & - & - & - & - & - & - \\
\hline Cephalothin & 5 & 5 & - & - & IA & - & 1 & 1 & - & - & IA & - \\
\hline Chloramphenicol & 8 & 8 & - & - & S & 100.0 & 4 & 4 & - & - & S & 100.0 \\
\hline Ciprofloxacin & 33 & 33 & - & - & $\mathrm{S}$ & 100.0 & 119 & 119 & - & - & S & 100.0 \\
\hline Clindamycin & 40 & 40 & - & - & S & 100.0 & 202 & 201 & - & 1 & S & 99.5 \\
\hline Daptomycin & - & - & - & - & - & - & 18 & 18 & - & - & S & 100.0 \\
\hline Doxycycline & 4 & 4 & - & - & - & - & 1 & 1 & - & - & - & - \\
\hline Erythromycin & 41 & 41 & - & - & S & 100.0 & 202 & 200 & 2 & - & S & 99.0 \\
\hline Gentamicin & 27 & 27 & - & - & S & 100.0 & 92 & 92 & - & - & S & 100.0 \\
\hline Imipenem & 5 & 5 & - & - & IA & - & - & - & - & - & - & - \\
\hline Linezolid & 6 & 6 & - & - & $S$ & 100.0 & 172 & 171 & - & 1 & S & 99.4 \\
\hline Meropenem & 2 & 2 & - & - & IA & - & - & - & - & - & - & - \\
\hline Oxacillin & 44 & 43 & - & 1 & S & 97.7 & 205 & 204 & - & 1 & S & 99.5 \\
\hline Penicillin G & 43 & 39 & - & 4 & S & 90.7 & 190 & 189 & - & 1 & S & 99.5 \\
\hline Piperacillin & - & - & - & - & - & - & 1 & 1 & - & - & IA & - \\
\hline Piperacillin/Taz & 1 & 1 & - & - & IA & - & - & - & - & - & - & - \\
\hline Quinupristin/Dal & - & - & - & - & - & - & 4 & 4 & - & - & - & - \\
\hline Rifampin & 4 & 4 & - & - & $S$ & 100.0 & 145 & 145 & - & - & S & 100.0 \\
\hline Teicoplanin & 13 & 13 & - & - & S & 100.0 & 35 & 35 & - & - & S & 100.0 \\
\hline Telithromycin & - & - & - & - & - & - & 17 & 17 & - & - & $\mathrm{S}$ & 100.0 \\
\hline Tetracycline & 18 & 18 & - & - & $S$ & 100.0 & 182 & 182 & - & - & S & 100.0 \\
\hline TMP-SMX & 36 & 36 & - & - & S & 100.0 & 197 & 197 & - & - & $\mathrm{S}$ & 100.0 \\
\hline Vancomycin & 27 & 27 & - & - & MIC only & - & 208 & 207 & - & 1 & S & 99.5 \\
\hline Tigecycline & - & - & - & - & - & - & 3 & 3 & - & - & IA & - \\
\hline Fusidic acid & - & - & - & - & - & - & 2 & 2 & - & - & IA & - \\
\hline
\end{tabular}

Abbreviations: S, susceptible; I, intermediate; R, resistance; Amoxicillin/Cla, amoxicillin/clavulanic acid; IA, inappropriate choice of antimicrobials; Ampicillin/Sul, ampicillin/sulbactam; Piperacillin/Taz, piperacillin/tazobactam; Quinupristin/Dal, quinupristin-dalfopristin; TMP-SMX, trimethoprim-sulfamethoxazole. 


\section{Journal of LABORATORY MEDICINE and QUALITY ASSURANCE}

Young Jin Ko et al • External Quality Assessment for Bacterial Culture

Table 7. Performance of antimicrobial susceptibility test for M1321 Staphylococcus aureus

\begin{tabular}{|c|c|c|c|c|c|c|c|c|c|c|c|c|}
\hline \multirow{2}{*}{ Antimicrobials } & \multicolumn{6}{|c|}{ Disk diffusion method } & \multicolumn{6}{|c|}{ Commercial broth dilution method } \\
\hline & Total & $S$ & I & $\mathrm{R}$ & Criteria & $\%$ & Total & $S$ & I & $\mathbf{R}$ & Criteria & $\%$ \\
\hline Amikacin & 1 & - & - & 1 & - & - & - & - & - & - & - & - \\
\hline Amoxicillin/Cla & 2 & 1 & - & 1 & IA & - & - & - & - & - & - & - \\
\hline Ampicillin & 5 & - & - & 5 & IA & - & - & - & - & - & - & - \\
\hline Ampicillin/Sul & 2 & - & - & 2 & IA & - & - & - & - & - & - & - \\
\hline Azithromycin & 1 & - & - & 1 & - & - & 6 & - & - & 6 & - & - \\
\hline Cefamandole & 2 & - & - & 2 & IA & - & - & - & - & - & - & - \\
\hline Cefazolin & 3 & - & - & 3 & IA & - & - & - & - & - & - & - \\
\hline Cefepime & 1 & - & - & 1 & IA & - & - & - & - & - & - & - \\
\hline Cefmetazole & 2 & - & - & 2 & IA & - & - & - & - & - & - & - \\
\hline Cefoperazone/Sul & 1 & - & - & 1 & IA & - & - & - & - & - & - & - \\
\hline Cefotaxime & 2 & - & - & 2 & IA & - & 1 & - & - & 1 & IA & - \\
\hline Cefotetan & 2 & - & - & 2 & IA & - & - & - & - & - & - & - \\
\hline Cefoxitin & 5 & - & - & 5 & IA & - & - & - & - & - & - & - \\
\hline Ceftazidime & 2 & - & - & 2 & IA & - & - & - & - & - & - & - \\
\hline Ceftriaxone & 7 & - & - & 7 & IA & - & - & - & - & - & - & - \\
\hline Cefuroxime sodium & 1 & - & - & 1 & IA & - & - & - & - & - & - & - \\
\hline Cephalothin & 4 & - & - & 4 & IA & - & - & - & - & - & - & - \\
\hline Chloramphenicol & 6 & 6 & - & - & - & - & 3 & 3 & - & - & - & - \\
\hline Ciprofloxacin & 33 & - & - & 33 & $\mathrm{R}$ & 100.0 & 76 & - & - & 76 & $\mathrm{R}$ & 100.0 \\
\hline Clarithromycin & 1 & - & - & 1 & - & - & - & - & - & - & - & - \\
\hline Clindamycin & 34 & - & - & 34 & $\mathrm{R}$ & 100.0 & 108 & - & - & 108 & $\mathrm{R}$ & 100.0 \\
\hline Daptomycin & - & - & - & - & - & - & 10 & 10 & - & - & S & 100.0 \\
\hline Erythromycin & 35 & - & - & 35 & $\mathrm{R}$ & 100.0 & 109 & - & - & 109 & $\mathrm{R}$ & 100.0 \\
\hline Gentamicin & 27 & - & - & 27 & $\mathrm{R}$ & 100.0 & 46 & - & - & 46 & $\mathrm{R}$ & 100.0 \\
\hline Imipenem & 6 & - & - & 6 & IA & - & - & - & - & - & - & - \\
\hline Linezolid & 4 & 3 & - & 1 & $S$ & 75.0 & 91 & 91 & - & - & S & 100.0 \\
\hline Meropenem & 3 & - & - & 3 & IA & - & - & - & - & - & - & - \\
\hline Oxacillin & 43 & - & - & 43 & $\mathrm{R}$ & 100.0 & 110 & - & - & 110 & $\mathrm{R}$ & 100.0 \\
\hline Penicillin G & 38 & - & - & 38 & $\mathrm{R}$ & 100.0 & 102 & - & - & 102 & $\mathrm{R}$ & 100.0 \\
\hline Piperacillin/Taz & 1 & - & - & 1 & IA & - & - & - & - & - & - & - \\
\hline Quinupristin/Dal & - & - & - & - & - & - & 5 & 5 & - & - & - & - \\
\hline Rifampin & 4 & 3 & - & 1 & $\mathrm{~S}$ & 75.0 & 69 & 69 & - & - & $\mathrm{S}$ & 100.0 \\
\hline Teicoplanin & 15 & 15 & - & - & $\mathrm{S}$ & 100.0 & 18 & 18 & - & - & $\mathrm{S}$ & 100.0 \\
\hline Telithromycin & - & - & - & - & - & - & 14 & - & - & 14 & $\mathrm{R}$ & 100.0 \\
\hline Tetracycline & 13 & - & - & 13 & $\mathrm{R}$ & 100.0 & 91 & - & - & 91 & $\mathrm{R}$ & 100.0 \\
\hline Tigecycline & - & - & - & - & - & - & 1 & 1 & - & - & - & - \\
\hline TMP-SMX & 35 & 32 & - & 3 & S & 91.4 & 106 & 106 & - & - & S & 100.0 \\
\hline Vancomycin & 25 & 25 & - & - & MIC only & - & 114 & 114 & - & - & S & 100.0 \\
\hline
\end{tabular}

Abbreviations: S, susceptible; I, intermediate; R, resistance; Amoxicillin/Cla, amoxicillin/clavulanic acid; IA, inappropriate choice of antimicrobials; Ampicillin/Sul, ampicillin/sulbactam; Cefoperazone/Sul, cefoperazone/sulbactam; Piperacillin/Taz, piperacillin/tazobactam; Quinupristin/Dal, quinupristin-dalfopristin; TMP-SMX, trimethoprim-sulfamethoxazole. 


\section{Journal of LABORATORY MEDICINE and QUALITY ASSURANCE}

\section{Young Jin Ko et al • External Quality Assessment for Bacterial Culture}

출하는데 오류가 많았다. 두 균주 모두 3세대 세팔로스포린, cefoxitin에 내성이지만, cefepime에는 감수성이었다. 이 균 주에 대해 extended-spectrum $\beta$-lactamase (ESBL) 검사 를 실시한 26기관 중 22 곳이 양성으로 보고했고, 이에 따라 cefepime 검사결과를 보고한 36기관 중 28곳이 내성으로 보고 하여 높은 오답률을 보였다. 이런 오류는 $\mathrm{MIC}$ 법 검사기관에 서만 발생했고, 특히 Vitek 2를 사용했다고 답한 기관이 16기 관 중 14 곳이 양성이라고 보고하여 한 가지 제품에 관련된 오 류일 가능성이 있었다. 이 균주는 CLSI 표준법으로 ESBL 확 인검사를 하면 음성이었다. E. coli와 E. cloacae 둘 다자동화 장비 $\mathrm{MIC}$ 법 사용기관의 $90.9 \%, 24 \%$ 기관이 비감수성을 보 고할 정도로 ertapenem에 내성이 있었지만, imipenem이나 meropenem에 완전히 감수성인데도 $\mathrm{MIC}$ 법 사용기관에서 meropenem은 $100 \%$ 감수성으로 보고한 반면 imipenem 내 성이 $15 \%, 5.3 \%$ 로 위내성이 많았다. 디스크확산법에서 $E$. coli의 imipenem/meropenem 억제대는 $23 \mathrm{~mm} / 24 \mathrm{~mm}, E$. cloacae의 imipenem/meropenem 억제대는 $23 \mathrm{~mm} / 23 \mathrm{~mm}$ 으로 새 CLSI 판독기준을 적용해도 감수성 범위이며 디스크 확산법 사용기관은 위내성 보고가 1 곳씩에 불과하여 자동화장
비 MIC법이 AmpC $\beta$-lactamase로 인한 imipenem 위내성에 취약하였다.

M1322 P. penneri는 전반적인 항균제감수성의 정답률이 매우 높았지만, imipenem 감수성 결과는 대오류가 많았다. 자 동화장비를 사용한 $\mathrm{MIC}$ 법 검사기관에서 imipenem 감수성 검사결과를 보고한 94 기관 중 35 곳 $(37.2 \%)$ 이 중등도 또는 내 성으로 보고하였다(Table 4). 장내세균 속에서 카바페넴 내 성을 정확히 검출하는 것에 대한 검사실 질향상이 필요하다. S. lugdunensis (Table 5), S. capitis (Table 6), S. aureus (Table 7), S. epidermidis (Table 8) 등 Staphylococcus 종에 대한 항균제 감수성검사에서 vancomycin 감수성검사를 디스 크확산법으로 실시하거나, cephalosporin 감수성검사를 실시 하는 것이 중요한 감점요인이었으며 이런 경향이 반복되어 향 후 더 개선이 필요하였다.

S1305 S. marcescens는 CRE 감시배양검사를 의뢰한 검체로 균종동정검사를 실시한 선별배지, 감수성검사 패 널, carbapenem MIC, modified Hodge test (MHT) 결과 와 사용한 배지 및 디스크 종류, EDTA 등 combined disk synergy 결과, PCR 등 방법과 결과를 코멘트에 입력하도

Table 8. Performance of antimicrobial susceptibility test for M1321 Staphylococcus epidermidis

\begin{tabular}{|c|c|c|c|c|c|c|c|c|c|c|c|c|}
\hline \multirow{2}{*}{ Antimicrobials } & \multicolumn{6}{|c|}{ Disk diffusion method } & \multicolumn{6}{|c|}{ Commercial broth dilution method } \\
\hline & Total & $S$ & I & $\mathbf{R}$ & Criteria & $\%$ & Total & $S$ & I & $\mathrm{R}$ & Criteria & $\%$ \\
\hline Cefoxitin & 1 & - & - & 1 & IA & - & - & - & - & - & - & - \\
\hline Chloramphenicol & 1 & 1 & - & - & - & - & 3 & 3 & - & - & - & - \\
\hline Ciprofloxacin & 1 & - & - & 1 & $\mathrm{R}$ & 100.0 & 48 & - & - & 48 & $\mathrm{R}$ & 100.0 \\
\hline Clindamycin & 2 & - & - & 2 & $\mathrm{R}$ & 100.0 & 94 & 2 & - & 92 & $\mathrm{R}$ & 97.9 \\
\hline Daptomycin & - & - & - & - & - & - & 11 & 11 & - & - & S & 100.0 \\
\hline Erythromycin & 2 & - & - & 2 & $\mathrm{R}$ & 100.0 & 95 & 2 & - & 93 & $\mathrm{R}$ & 97.9 \\
\hline Gentamicin & 1 & - & - & 1 & $\mathrm{R}$ & 100.0 & 38 & - & - & 38 & $\mathrm{R}$ & 100.0 \\
\hline Linezolid & 1 & 1 & - & - & $\mathrm{S}$ & 100.0 & 84 & 84 & - & - & $\mathrm{S}$ & 100.0 \\
\hline Oxacillin & 1 & - & - & 1 & $\mathrm{R}$ & 100.0 & 95 & - & - & 95 & $\mathrm{R}$ & 100.0 \\
\hline Penicillin G & 2 & - & - & 2 & $\mathrm{R}$ & 100.0 & 93 & 1 & - & 92 & $\mathrm{R}$ & 98.9 \\
\hline Quinupristin/Dal & - & - & - & - & - & - & 3 & 3 & - & - & - & - \\
\hline Rifampin & 1 & - & - & 1 & $\mathrm{R}$ & 100.0 & 74 & - & - & 74 & $\mathrm{R}$ & 100.0 \\
\hline Teicoplanin & - & - & - & - & - & - & 16 & 16 & - & - & $\mathrm{S}$ & 100.0 \\
\hline Telithromycin & - & - & - & - & - & - & 5 & 1 & - & 4 & - & - \\
\hline Tetracycline & 1 & 1 & - & - & $\mathrm{S}$ & - & 90 & 90 & - & - & S & 100.0 \\
\hline Tigecycline & - & - & - & - & - & - & 1 & 1 & - & - & - & - \\
\hline TMP-SMX & 2 & - & - & 2 & $\mathrm{R}$ & 100.0 & 94 & - & - & 94 & $\mathrm{R}$ & 100.0 \\
\hline Vancomycin & 1 & 1 & - & - & MIC only & - & 97 & 97 & - & - & $\mathrm{S}$ & 100.0 \\
\hline
\end{tabular}

Abbreviations: S, susceptible; I, intermediate; R, resistance; IA, inappropriate choice of antimicrobials; Quinupristin/Dal, quinupristindalfopristin; TMP-SMX, trimethoprim-sulfamethoxazole. 
Journal of LABORATORY MEDICINE and QUALITY ASSURANCE

Young Jin Ko et al • External Quality Assessment for Bacterial Culture

Table 9. Methods of carbapenem susceptibility tests and kinds of carbapenem for carbapenem-resistant Enterobacteriaceae

\begin{tabular}{|c|c|c|c|c|c|}
\hline \multirow{2}{*}{ Methods } & \multirow{2}{*}{ Carbapenems } & \multirow{2}{*}{ No. of laboratory } & \multicolumn{3}{|c|}{ Modified Hodge test } \\
\hline & & & Media & Carbapenems & No. of laboratory \\
\hline \multirow[t]{3}{*}{ VITEK-2 } & ETP/IMP & 25 & MHA & ETP/IMP & 1 \\
\hline & ETP/MRP & 2 & & ETP/MRP & 1 \\
\hline & IMP/MRP & 1 & & ETP & 9 \\
\hline \multirow[t]{3}{*}{ MicroScan } & ETP/IMP/MRP & 1 & & IMP & 2 \\
\hline & IMP/MRP & 4 & & MRP & 4 \\
\hline & IMP & 3 & MacConkey & ETP/MRP & 1 \\
\hline Phoenix & IMP/MRP & 1 & & IMP & 4 \\
\hline \multirow[t]{5}{*}{ Disk diffusion } & ETP/IMP/MRP & 1 & & & \\
\hline & ETP/IMP & 3 & & & \\
\hline & IMP/MRP & 3 & & & \\
\hline & ETP & 1 & & & \\
\hline & IMP & 1 & & & \\
\hline \multirow[t]{4}{*}{ E-test } & ETP/IMP/MRP & 1 & & & \\
\hline & ETP/IMP & 1 & & & \\
\hline & IMP/MRP & 2 & & & \\
\hline & IMP & 4 & & & \\
\hline Total & & 54 & Total & & 22 \\
\hline
\end{tabular}

Abbreviations: ETP, ertapenem; IMP, imipenem; MHA, Mueller-Hinton agar; MRP, meropenem.

록 요구하였다. 균종 동정을 실패한 기관은 없었으나, $\mathrm{CRE}$ surveillance의 적절한 검사과정을 진행한 결과를 입력한 기관이 50곳(69.4\%)이었다. 이 균주는 Verona Integronencoded Metallo- $\beta$-lactamase-2 (VIM-2)를 생산하는 carbapenemase-producing Enterobacteriaceae (CPE)로서, MHT, EDTA synergy검사, dipicolinic acid 억제검사에 모두 양성소견이었다. 50 기관 중 $\mathrm{CPE}$ (22), Metallo- $\beta$-lactamase 양성(16), VIM-2 양성(4)까지 보고한 45곳은 $\mathrm{CPE}$ 감시배양 을 할 수 있는 적절한 수행능을 보였다. $\mathrm{CRE}$ 를 선별하고 확 인하는데 다양한 검사와 carbapenem 조합을 사용하고 있었 지만 $\mathrm{MHT}$ 를 실시한 기관들은 $\mathrm{CPE}$ 인 것을 정확히 검출한 것 에 비해 carbapenem 감수성이라고 보고한 2기관은 디스크 확산법, E-test만을 시행하고 있어서 $\mathrm{CRE}$ 선별 및 확인검사 에 MHT를 필수적으로 실시할 필요가 있었다. MHT에 사용 하는 디스크과 배지를 기술한 기관들 중 carbapenem 디스크 는 ertapenem 또는 ertapenem 포함 복수의 carbapenem, meropenem, imipenem이 각각 $12,4,6$ 곳으로서 기본적 으로 ertapenem을 사용하는 곳이 가장 많았지만, CLSI에 서 권장하지 않는 imipenem만 사용하는 기관도 6 기관 있었 고, MacConkey agar를 사용한 5곳 중 4곳은 imipenem 디
스크를 사용하고 있었다(Table 9). 포도당 비발효 그람음성간 균인 M1311은 P. aeruginosa에 항균력이 없는 tigecycline, trimethoprim-sulfamethoxazole, 1, 2세대 cephalosporins의 감수성까지 보고하는 기관이 부적합결과의 원인이었고(Table 10), S. maltophilia는 ceftazidime과 ticarcillin-clavulanate 에 디스크확산법을 사용하거나 CLSI에서 권장하지 않는 부 적절한 항균제에 대해 감수성 결과를 보고하는 것이 가장 빈 번한 부적절한 결과의 원인이었다. 이 균종은 trimethoprimsulfamethoxazole에 대한 정답률은 $100 \%$ 였지만, 나머지 ceftazidime, ticarcillin-clavulanate, levofloxacin은 88-94\% 정도로 다른 그람음성간균에 비해 정확도가 떨어졌다(Table 11).

\section{고찰}

2013년에는 특수세균 신빙도조사 참여기관 수가 72 기관으 로 증가하여 영양요구도가 까다롭고 동정이 어려운 세균, 미 호기성세균, 혐기성세균, 사상형진균 등의 병원체를 배양하고 동정하는 외부정도관리 분야를 넓힐 수 있었다. 세균 분야의 회원기관 수나 응답률은 2012년 신빙도조사 때와 유사하였다 


\section{Journal of LABORATORY MEDICINE and QUALITY ASSURANCE}

Young Jin Ko et al • External Quality Assessment for Bacterial Culture

Table 10. Performance of antimicrobial susceptibility test for M1311 Pseudomonas aeruginosa

\begin{tabular}{|c|c|c|c|c|c|c|c|c|c|c|c|c|}
\hline \multirow{2}{*}{ Antimicrobials } & \multicolumn{6}{|c|}{ Disk diffusion method } & \multicolumn{6}{|c|}{ Commercial broth dilution method } \\
\hline & Total & S & I & $\mathrm{R}$ & Criteria & $\%$ & Total & $\mathrm{S}$ & I & $\mathrm{R}$ & Criteria & $\%$ \\
\hline Amikacin & 27 & 22 & 4 & 1 & S & 81.5 & 158 & 155 & 2 & 1 & $\mathrm{~S}$ & 98.1 \\
\hline Amoxicillin/Cla & - & - & - & - & - & - & 1 & - & - & 1 & IA & - \\
\hline Ampicillin & 2 & - & - & 2 & IA & - & 2 & - & - & 2 & IA & - \\
\hline Ampicillin/Sul & 1 & - & - & 1 & IA & - & 4 & - & - & 4 & IA & - \\
\hline Aztreonam & 14 & 1 & 7 & 6 & $\mathrm{I} / \mathrm{R}$ & 92.9 & 132 & - & 8 & 124 & $\mathrm{I} / \mathrm{R}$ & 100.0 \\
\hline Cefazolin & 1 & - & - & 1 & IA & - & 1 & - & - & 1 & IA & - \\
\hline Cefepime & 7 & - & - & 7 & $\mathrm{R}$ & 100.0 & 148 & 1 & 1 & 146 & $\mathrm{R}$ & 98.6 \\
\hline Cefotaxime & 6 & - & - & 6 & - & - & 6 & - & - & 6 & - & - \\
\hline Cefotetan & 1 & - & - & 1 & IA & - & - & - & - & - & - & - \\
\hline Cefoxitin & - & - & - & - & - & - & 1 & - & - & 1 & IA & - \\
\hline Ceftazidime & 25 & 5 & 4 & 16 & $\mathrm{R}$ & 64.0 & 159 & 1 & - & 158 & $\mathrm{R}$ & 99.4 \\
\hline Ceftriaxone & 8 & - & - & 8 & - & - & - & - & - & - & - & - \\
\hline Cefuroxime axetil & 1 & - & - & 1 & IA & - & - & - & - & - & - & - \\
\hline Cefuroxime sodium & 1 & - & - & 1 & IA & - & - & - & - & - & - & - \\
\hline Chloramphenicol & 1 & - & - & 1 & IA & - & - & - & - & - & - & - \\
\hline Ciprofloxacin & 26 & 25 & - & 1 & S & 96.2 & 155 & 154 & - & 1 & S & 99.4 \\
\hline Colistin & 2 & 2 & - & - & S & 100.0 & 22 & 22 & - & - & S & 100.0 \\
\hline Gentamicin & 22 & 18 & 4 & - & S/I & 100.0 & 160 & 137 & 22 & 1 & $\mathrm{~S} / \mathrm{I}$ & 99.4 \\
\hline Imipenem & 24 & 1 & - & 23 & $\mathrm{R}$ & 95.8 & 160 & 1 & - & 159 & $\mathrm{R}$ & 99.4 \\
\hline Levofloxacin & 6 & 6 & - & - & S & 100.0 & 27 & 26 & - & 1 & S & 96.3 \\
\hline Meropenem & 11 & - & - & 11 & $\mathrm{R}$ & 100.0 & 124 & 1 & - & 123 & $\mathrm{R}$ & 99.2 \\
\hline Minocycline & - & - & - & - & - & - & 1 & 1 & - & - & IA & - \\
\hline Piperacillin & 20 & 1 & - & 19 & $\mathrm{R}$ & 95.0 & 138 & 1 & - & 137 & $\mathrm{R}$ & 99.3 \\
\hline Piperacillin/Taz & 9 & 1 & 1 & 7 & $\mathrm{R}$ & 77.8 & 146 & 2 & 2 & 142 & $\mathrm{R}$ & 97.3 \\
\hline Ticarcillin & 1 & 1 & - & - & $\mathrm{R}$ & 0 & 4 & - & - & 4 & $\mathrm{R}$ & 100.0 \\
\hline Ticarcillin/Cla & 1 & - & - & 1 & $\mathrm{R}$ & 100.0 & 11 & - & - & 11 & $\mathrm{R}$ & 100.0 \\
\hline Tobramycin & 16 & 15 & - & 1 & $\mathrm{~S}$ & 93.8 & 45 & 43 & - & 2 & $\mathrm{~S}$ & 95.6 \\
\hline TMP-SMX & 4 & - & - & 4 & IA & - & 3 & - & - & 3 & IA & - \\
\hline Tigecycline & - & - & - & - & - & - & 2 & - & - & 2 & IA & - \\
\hline
\end{tabular}

Abbreviations: S, susceptible; I, intermediate; R, resistance; Amoxicillin/Cla, amoxicillin/clavulanic acid; IA, inappropriate choice of antimicrobials; Ampicillin/Sul, ampicillin/sulbactam; Piperacillin/Taz, piperacillin/tazobactam; Ticarcillin/Cla, ticarcillin/clavulanic acid; TMP-SMX, trimethoprim-sulfamethoxazole.

[8]. 검체별로 임상적 배경을 상세하게 제공하여 이에 따라 동 정수준을 다르게 적용할 수 있도록 하였다. 그람음성간균 장내 세균 속에 대해서는 배양과 동정검사 수행능이 우수한데 비해 작은 집락의 베타용혈성 viridans streptococci와 Lancefield group A, B가 아닌 베타용혈성 streptococci, 비발효 그람음 성간균, 그람음성구균에 대해서는 종수준 동정률이 낮고, 정 답률도 낮았다. 이는 이들 그룹의 균들이 여전히 수기동정에
많이 의존하거나 상품화된 동정 제품을 사용해도 동정 정확도 가 떨어진다는 점이 중요한 원인일 것이다. 배양동정에 있어 서 종동정 수준이 $90 \%$ 이하로 낮은 균종들은 S. lugdunensis, C. striatum, C. glabrata, M. pachydermatis, S. capitis, $L$. monocytogenes, P. penneri, A. hydrophila 등으로 이들 균 종의 종수준 동정 정확도를 향상시킬 필요가 있었다. 특히 $S$. lugdunensis가 clumping factor (slide coagulase)가 양성이 
Journal of LABORATORY MEDICINE and QUALITY ASSURANCE

Young Jin Ko et al • External Quality Assessment for Bacterial Culture

Table 11. Performance of antimicrobial susceptibility test for M1311 Stenotrophomonas maltophilia

\begin{tabular}{|c|c|c|c|c|c|c|c|c|c|c|c|c|}
\hline \multirow{2}{*}{ Antimicrobials } & \multicolumn{6}{|c|}{ Disk diffusion method } & \multicolumn{6}{|c|}{ Commercial broth dilution method } \\
\hline & Total & $\mathrm{S}$ & $\mathrm{I}$ & $\mathrm{R}$ & Criteria & $\%$ & Total & $\mathrm{S}$ & I & $\mathrm{R}$ & Criteria & $\%$ \\
\hline Amikacin & 4 & 1 & - & 3 & IA & - & 1 & - & - & 1 & IA & - \\
\hline Amoxicillin/Cla & 2 & - & - & 2 & IA & - & - & - & - & - & - & - \\
\hline Ampicillin & 2 & - & - & 2 & IA & - & - & - & - & - & - & - \\
\hline Aztreonam & 4 & - & - & 4 & IA & - & 1 & - & - & 1 & IA & - \\
\hline Cefaclor & 1 & - & - & 1 & IA & - & - & - & - & - & - & - \\
\hline Cefazolin & 2 & - & - & 2 & IA & - & - & - & - & - & - & - \\
\hline Cefepime & - & - & - & - & - & - & 1 & - & 1 & - & IA & - \\
\hline Cefoperazone & 1 & 1 & - & - & IA & - & - & - & - & - & - & - \\
\hline Cefotaxime & 1 & - & - & 1 & IA & - & - & - & - & - & - & - \\
\hline Cefotetan & 1 & 1 & - & - & IA & - & - & - & - & - & - & - \\
\hline Ceftazidime & 9 & 1 & - & 8 & MIC only & - & 17 & 12 & 3 & 2 & $\mathrm{I} / \mathrm{S}$ & 88.2 \\
\hline Ceftriaxone & 4 & - & - & 4 & IA & - & - & - & - & - & - & - \\
\hline Ciprofloxacin & 9 & 5 & 2 & 2 & IA & - & 1 & - & - & 1 & IA & - \\
\hline Colistin & 1 & - & - & 1 & IA & - & - & - & - & - & - & - \\
\hline Doxycycline & 1 & - & - & 1 & IA & - & - & - & - & - & - & - \\
\hline Gentamicin & 6 & 2 & - & 4 & IA & - & 1 & - & - & 1 & IA & - \\
\hline Imipenem & 5 & - & - & 5 & IA & - & 1 & - & - & 1 & IA & - \\
\hline Levofloxacin & 9 & 8 & - & 1 & S & 88.9 & 17 & 16 & - & 1 & S & 94.1 \\
\hline Minocycline & 5 & 4 & - & 1 & - & - & 2 & 1 & - & 1 & - & - \\
\hline Netilmicin & 1 & - & - & 1 & IA & - & - & - & - & - & - & - \\
\hline Piperacillin & 1 & 1 & - & - & IA & - & - & - & - & - & - & - \\
\hline Piperacillin/Taz & 1 & 1 & - & - & IA & - & - & - & - & - & - & - \\
\hline Teicoplanin & 1 & - & - & 1 & IA & - & - & - & - & - & - & - \\
\hline Ticarcillin/Cla & - & - & - & - & MIC only & - & 8 & 7 & - & 1 & S & 87.5 \\
\hline Tobramycin & 2 & - & - & 2 & IA & - & - & - & - & - & - & - \\
\hline TMP-SMX & 18 & 18 & - & - & S & 100.0 & 40 & 40 & - & - & S & 100.0 \\
\hline Vancomycin & 1 & 1 & - & - & IA & - & - & - & - & - & - & - \\
\hline
\end{tabular}

Abbreviations: S, susceptible; I, intermediate; R, resistance; IA, inappropriate choice of antimicrobials; Amoxicillin/Cla, amoxicillin/clavulanic acid; Piperacillin/Taz, piperacillin/tazobactam; Ticarcillin/Cla, ticarcillin/clavulanic acid; TMP-SMX, trimethoprim-sulfamethoxazole.

기 때문에 S. aureus의 coagulase를 검출하는데 기초한 라 텍스응집법 검사를 해서 동정하는 기관들에서 많은 동정오류 가 발생하였다. 라텍스응집법을 사용하는 기관들은 집락을 관 찰할 때 S. aureus인지 더 세심하게 판독할 필요가 있다. $V$. vulnificus 검체에서는 대변 검체의 정상상재균으로 섞은 $\mathrm{E}$. coli를 동정하여 보고한 것이 동정 정확도를 낮춘 중요한 이유 였는데, 임상 검체를 배양할 때 검체별 중요한 병원성 균종과 정상상재균을 구분하여 동정하는 수행능을 평가할 수 있었다. P. penneri는 P. vulgaris로 동정한 기관이 59곳(22.6\%)이었 는데 P. penneri는 P. vulgaris처럼 piperacillin, amoxicillin, ampicillin, cefoperazone, cefuroxime에는 내성으로 항균제 감수성 양상으로는 감별이 어렵다. 하지만 indole 양성인 $P$. vulgaris에 비해 indole이 음성인 것이 특징인데 indole이 포함 되지 않은 자동화 동정장비 키트들이 동정오류에 취약한 것으 로 추정되었다.

그람양성알균 항균제감수성검사에서 가장 빈번하게 반복되 는 오류는 S. aureus의 beta-lactam에 대한 감수성검사에서 penicillin, oxacillin 두 가지 항균제에 대해서만 보고하면 충분 한데도 일차 감수성검사대상인 penicillin, oxacillin을 검사하 지 않으면서 다른 beta-lactam에 대한 감수성검사결과를 보 


\section{Journal of LABORATORY MEDICINE and QUALITY ASSURANCE}

Young Jin Ko et al • External Quality Assessment for Bacterial Culture

고하는 것이었다. 또 cefoxitin 디스크확산법을 실시한 기관 중 상당수가 oxacillin 감수성이 아니라 cefoxitin 감수성으로 보 고함으로써 부적합 판정을 받았다. Cefoxitin은 oxacillin에 대 한 감수성을 대신 측정하기 위한 대용제(surrogate)일 뿐이므 로 이런 보고는 부적합하다고 평가한다[4]. 디스크확산법을 실시하는 기관에서 vancomycin, teicoplanin 감수성검사를 디 스크확산법으로 실시하는 오류가 대표적인 부적합결과의 원 인이었다. 디스크확산법을 사용하는 기관은 vancomycin agar screen법이나 vancomycin E-test 등으로 감수성검사를 보완 할 수 있는 방안을 마련할 필요가 있었다.

그람음성막대균에 대한 항균제감수성검사에서 M1301의 E. cloacae와 E. coli는 AmpC $\beta$-lactamase로 인한 광범위 베타 락탐계 항생제 내성과 ertapenem 내성이 있었는데 이를 검출 하는데 오류가 많았다. AmpC $\beta$-lactamase의 특징상 두 균주 모두 3세대 세팔로스포린, cefoxitin에 내성이지만, cefepime 에는 감수성인데도[9], $\mathrm{ESBL}$ 양성으로 판독한 기관들은 cefepime 내성으로 보고했는데 VITEK2를 사용한 기관들이어 서 $\mathrm{ESBL}$ 판독오류가 감수성 판독오류로 연결되었다. VITEK 자동화기기를 사용하는 경우 $\mathrm{AmpC}$ 양성균주의 $\mathrm{ESBL}$ 위양 성에 대한 주의가 필요하다[10]. M1301 균주처럼 ertapenem 에만 내성인 장내세균들은 국내에서는 대부분 $\mathrm{AmpC} \beta^{-}$ lactamase에 porin loss가 동반된 경우로서[11] 카바페넴 분 해효소에 의한 내성을 검출하는데 ertapenem은 특이도가 낮 다. P. penneri의 imipenem 위내성은 대부분 VITEK2를 사용 하는 기관에서 나타나고 있다. 이번 조사에 사용된 균주는 획 득내성이 없어서 ampicillin, 1, 2세대 세팔로스포린을 제외한 베타락탐계 항생제에 모두 감수성이었기 때문에 ertapenem, meropenem에 모든 기관이 감수성으로 보고하였다. VITEK 자동화장비 감수성검사가 P. mirabilis의 imipenem 위내성 에 취약하다는 것은 보고된 바 있고[12], CLSI도 Proteus, Providentia, Morganella종들의 imipenem 위내성에 대해 경고하고 있다[4]. 따라서 임상검사실에서는 이들 세 균종 에서 imipenem 위내성을 보고하는 대오류의 위험이 있다 는 것을 반드시 알고 있어야 한다. 비발효성 그람음성막대균 에서는 항균제 선택 오류가 많고, 희석법 만 사용해야 하는데 도 디스크확산법으로 검사하여 보고하는 것이 문제였다. $S$. maltophilia 등 비발효 그람음성간균은 CLSI에서 감수성검사 를 권장하는 약제가 ceftazidime, minocycline, levofloxacin, trimethoprim-sulfamethoxazole, ticarcillin-clavulanate, chloramphenicol에 불과하고, 이 중 ceftazidime과 ticarcillinclavulanate는 디스크확산법을 사용해서는 안 된다[4]. 비발 효 그람음성막대균에서 적절한 항균제와 감수성검사방법을
선택할 수 있는 수행능을 더 항상시킬 필요가 있었다.

최근 국내 대형병원뿐 아니라 중소형병원에서도 카바페넴분 해효소 생산 장내세균의 확산과 유행이 큰 문제가 되고 있어서 〔13-15] 임상검사실에서는 이를 민감하고 정확하게 검출하고 동정하는 것이 중요하다. MHT를 실시하는 기관들은 VIM-2 양성 S. marcescens를 CPE까지 검출하는데 우수한 수행능을 보였다. 이 균주를 카바페넴 감수성으로 보고한 2기관은 $\mathrm{MHT}$ 를 실시하지 않았던 곳으로 $\mathrm{MHT}$ 가 $\mathrm{CRE}$ 를 검출하는 능력과 도 관련이 있음을 알 수 있었다. 따라서 임상검사실에서 $\mathrm{CPE}$ 선별 및 확인을 위해 $\mathrm{MHT}$ 를 필수적으로 실시할 필요가 있었 다. 하지만 MHT에 사용하는 배지와 디스크 종류는 CLSI에서 권장하는 것과는 달리 MacConkey 배지나 imipenem 디스크 를 사용하는 기관들이 있어서 이를 표준화할 필요가 있었다.

결론적으로 2013년 임상미생물학 신빙도조사는 항균제 내 성균 검출, 특수 세균에 배양 및 동정에 대한 영역을 확대하여 참여기관에 더 포괄적인 외부정도관리프로그램을 제공할 수 있었다. 종동정에서 지시서의 검체 종류와 맞지 않은 균종을 병원균으로 동정하는 것이 정확도를 떨어뜨리는 요인이었고, Staphylococcus 종의 항균제 감수성검사에서 항균제 선정과 감수성검사방법을 잘못 선택하는 오류가 빈번하여 향후 이에 대한 개선이 필요하였다.

\section{REFERENCES}

1. Jones RN, Glick T, Sader HS, Flamm RK, Ross JE, Rhomberg PR, et al. Educational antimicrobial susceptibility testing as a critical component of microbiology laboratory proficiency programs: American Proficiency Institute results for 2007-2011. Diagn Microbiol Infect Dis 2013;75:357-60.

2. Snell JJ, Brown DF, Perry SF, George R. Antimicrobial susceptibility testing of enterococci: results of a survey conducted by the United Kingdom National External Quality Assessment Scheme for Microbiology. J Antimicrob Chemother 1993;32:401-11.

3. Chaitram JM, Jevitt LA, Lary S, Tenover FC; WHO Antimicrobial Resistancce Group. The World Health Organization's External Quality Assurance System Proficiency Testing Program has improved the accuracy of antimicrobial susceptibility testing and reporting among participating laboratories using NCCLS methods. J Clin Microbiol 2003;41:2372-7. 


\section{Journal of LABORATORY MEDICINE and QUALITY ASSURANCE}

Young Jin Ko et al • External Quality Assessment for Bacterial Culture

4. Clinical and Laboratory Standards Institute. Performance standards for antimicrobial susceptibility testing: 24th informational supplement, M100-S24. Wayne (PA): Clinical and Laboratory Standards Institute, 2014.

5. EUCAST. Breakpoint tables for interpretation of MICs and zone diameters (http://www.eucast.org/fileadmin/ src/media/PDFs/EUCAST_files/Breakpoint_tables/ Breakpoint_table_v_4.0.pdf Accessed January 1, 2014).

6. Clinical and Laboratory Standards Institute. Performance standards for antimicrobial susceptibility testing; 23th informational supplement, M100-S23. Wayne (PA): Clinical and Laboratory Standards Institute, 2013.

7. Burton JP, Dixon JL, Reid G. Detection of Bifidobacterium species and Gardnerella vaginalis in the vagina using PCR and denaturing gradient gel electrophoresis (DGGE). Int J Gynaecol Obstet 2003;81:61-3.

8. Kim MN, Kim MS, Kim SJ, Kim SI, Kim EJ, Kim CK, et al. Annual report on external quality assessment of clinical microbiology laboratory in Korea (2012). J Lab Med Qual Assur 2013;35:S211-46.

9. Spellerberg B, Brandt C. Special phenotypic methods for detecting antibacterial resistance. In: Swenson JM, Patel JB, Jorgensen JH, editors. Manual of clinical microbiology. 10th ed. Washington (DC): ASM press, 2011; 1168.

10. Doern GV, Brueggemann AB, Perla R, Daly J, Halkias D, Jones RN, et al. Multicenter laboratory evaluation of the bioM?rieux Vitek antimicrobial susceptibility testing system with 11 antimicrobial agents versus members of the family Enterobacteriaceae and Pseudomonas aeruginosa. J Clin Microbiol 1997;35:2115-9.

11. Lee K, Lee M, Shin JH, Lee MH, Kang SH, Park AJ, et al. Prevalence of plasmid-mediated AmpC beta-lactamases in Escherichia coli and Klebsiella pneumoniae in Korea. Microb Drug Resist 2006;12:44-9.

12. Steward CD, Mohammed JM, Swenson JM, Stocker SA, Williams PP, Gaynes RP, et al. Antimicrobial susceptibility testing of carbapenems: multicenter validity testing and accuracy levels of five antimicrobial test methods for detecting resistance in Enterobacteriaceae and Pseudomonas aeruginosa isolates. J Clin Microbiol 2003;41:351-8.

13. Kim MN, Yong D, An D, Chung HS, Woo JH, Lee K, et al. Nosocomial clustering of NDM-1-producing Klebsiella pneumoniae sequence type 340 strains in four patients at a South Korean tertiary care hospital. J Clin Microbiol 2012;50:1433-6.

14. Hong SK, Yong D, Kim K, Hong SS, Hong SG, Khosbayar T, et al. First outbreak of KPC-2-producing Klebsiella pneumonia sequence type 258 in a hospital in South Korea. J Clin Microbiol 2013;51:3877-9.

15. Korea National Institute of Health. Korean Antimicrobial Resistance Monitoring System 2012 Annual Report (http://www.cdc.go.kr/CDC/cms/cmsFileDownload.jsp? fid $=136 \&$ cid $=21224 \&$ field Name $=$ attachGrp\&index $=4$ Accessed June 13, 2014). 
임상미생물학분과 신빙도조사 결과보고(2013)

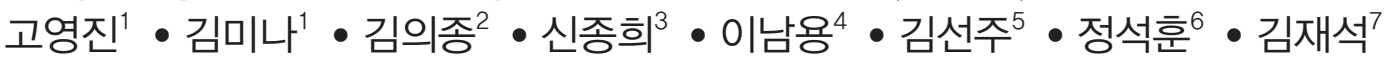

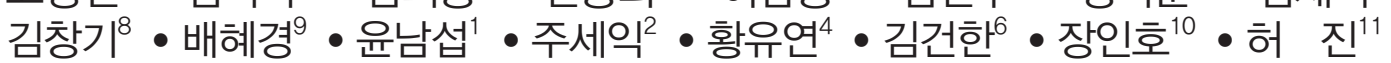
대한임상검사정도관리협회 임상미생물분과위원회

${ }^{1}$ 울산대학교 의과대학 서울아산병원 진단검사의학과, ${ }^{2}$ 서울대학교 의과대학 서울대병원 진단검사의학과, ${ }^{3}$ 전 남대학교 의과대학 전남대병원 진단검사의학과, ${ }^{4}$ 성균관대학교 의과대학 삼성서울병원 진단검사의학과, ${ }^{5}$ 경상 대학교 의과대학 경상대병원 진단검사의학과, ${ }^{6}$ 연세대학교 의과대학 강남세브란스병원 진단검사의학과, ${ }^{7}$ 한림 대학교 의과대학 강동성심병원 진단검사의학과, ${ }^{8}$ 결핵연구원 진단검사의학과, ${ }^{9}$ 녹십자 의료재단 진단검사의학 과, ${ }^{10}$ 연세대학교 원주의과대학 원주기독병원 진단검사의학과, ${ }^{11}$ 고려대학교 의과대학 고려대학교안산병원 진 단검사의학과

대한임상정도관리협회의 미생물 분과에서는 매년 외부정도관리(신빙도조사)를 3회 실시하고 있다. 각각의 기간에 4가지 세균과 한가지 진균으로 구성된 세가지 종류의 세트가 균배양 동정과 감수성 검사를 위해 전국으로 배분되었다. 340 검사기관이 참여하였고 이 중 1차에서 330기관(97.0\%), 2 차에서 331기관(97.4\%), 3차에서 331기관(97.4\%)이 회신하였다. 세균동정에서는 그람음성막대균 과 Staphylococcus aureus, Staphylococcus epidermidis, Staphylococcus capitis, Streptococcus agalactiae, Listeria monocytogenes, Candida species의 동정 정확도는 acceptable\%가 95\% 이 상이었다. 하지만 Staphylococcus Iugdunensis와 Corynebacterium striatum, Vibrio vulnificus, Aeromonas hydrophila, Cryptococcus neoformans, Malassezia pachydermatis의 동정 정확도는 acceptable\%가 95.4\%과 89.9\%, 50.7\%, 91.3\%, 93.6\%, 93.9\%로 상대적으로 부정확하였다. 반코마 이신 내성 장구균(vancomycin-resistant enterococci)과 메티실린 내성 황색포도상구균(methicillinresistant S. aureus)의 감시배양은 각각 $95.4 \%$ 와 $93.9 \%$ 의 기관에서 정답을 보고하였다. AmpC $\beta$-lactamase에 의한 카바페넴 위내성, Staphylococcus 종에서 반코마이신에 대한 디스크 확산법의 보고, S. Iugdunensis에서 oxacilin과 페니실린 감수성검사, Proteus 종에서 imipenem 위내성이 부적 절한 결과의 흔한 원인이었다. Corynebacterium 종과 Vibrio 종은 종수준 동정 정확도를 개선할 필 요가 있다. Staphylococcus 종의 항균제 감수성검사에서 반코마이신의 감수성검사에서 디스크 확 산법을 잘못 선택하는 오류가 빈번하였다.

(J Lab Med Qual Assur 2014;36:122-139)

교신저자: 김미나

우)138-736 서울시 송파구 올림픽로 43길 88, 울산대학교 의과대학 서울아산병원 진단검사의학과 Tel: 02)3010-4511, Fax: 02)478-0884, E-mail: mnkim@amc.seoul.kr 